Arteterapia. Papeles de arteterapia y educación para inclusión social ISSN-e 1988-8309

http://dx.doi.org/10.5209/ARTE.57575

\title{
Arteterapia y género. Un espacio propio: de lazos, cajas y naufragios
}

\author{
Sofía Martín ${ }^{1}$
}

Recibido: 30 de mayo de 2017 / Aceptado: 15 de julio de 2017

Resumen. Este artículo parte de la metáfora del espacio propio como marco de referencia propicio para el acompañamiento arte terapéutico a mujeres y grupos de mujeres, especialmente a aquellas que han sufrido traumas graves a lo largo de sus vidas. Este marco de trabajo acoge diferentes cuestiones como las relaciones entre la configuración de la identidad femenina y la gestación de un self verdadero sano, en el sentido winnicottiano; la construcción y vivencia de la identidad de género; la relación con la propia imagen y el cuerpo así como con la mirada propia y ajena sobre estas construcciones; o la relación con la soledad como lugar de empoderamiento personal. Se abordan algunos aspectos sobre cómo poder acompañar desde el arteterapia la recuperación de las capacidades resilientes y el hallazgo de ese espacio propio legitimador y seguro que nos capacita para el ejercicio de la libertad y la creación. Palabras clave: identidad; género; self verdadero; espacio propio; espacio vincular y relacional; soledad; trauma; resiliencia.

\section{[en] Art Therapy and Gender. A Room of One's Own: About Boxes, Ties and Shipwrecks.}

\begin{abstract}
This article sprouts from the space of one's own metaphor as the appropriate frame of reference for the art-therapeutic accompaniment of women, individually or in groups, especially those who have suffered severe trauma along their lives. This frame of work involves diverse aspects such as the links between the configuration of the female subjectivity and de development of a healthy concept of one's self, from a Winnicott perspective; the construction and experiencing of gender identity; the relationship with one's own image and body as well as with the internal and external look on those constructions or the connection with solitude as a personal empowering space. The article tackles issues such as how to enable the art therapy to accompany the recovery of resilience skills and the discovery of one's legitimate and safe own space to enable the individual to exercise its freedom and creative potencial.
\end{abstract}

Key words: identity; gender; true self; own space; bonding space; solitude; trauma; resilience.

Cómo citar: Martín, S. (2017). Arteterapia y género. Un espacio propio: de lazos, cajas y naufragios, en Arteterapia. Papeles de arteterapia y educación para inclusión social 12, 243-256.

Arteterapeuta, Acompañante Terapéutica, Antropóloga y Educadora Social. Experta en Género y Salud Mental. Formaciones en terapias y abordajes corporales. Colaboradora Honorífica del Dpto. de Didáctica de la Expresión Plástica de la Facultad de Educación de la UCM. Fundadora de LaVincular.

E-mail sofia.kalika@gmail.com 


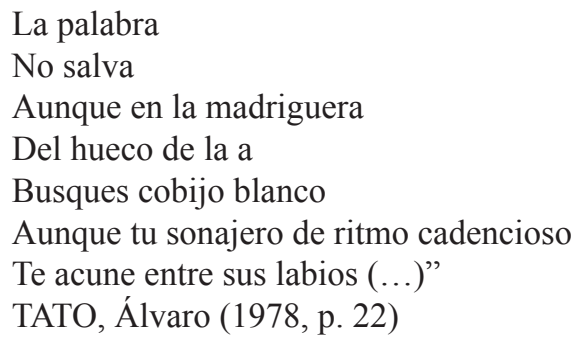

En 1929 los colegas escritores de Virginia Wolf, le pidieron que escribiera un texto sobre las mujeres y la literatura. Tras un exhaustivo e incisivo análisis de la sociedad de la época, ella resalta la idea de que las mujeres para hacer literatura necesitan un cuarto propio y solvencia/independencia económica (Woolf, V [(1929)2014]. Sin embargo, esta imagen, es también símbolo de algo más profundo y complejo. Este cuarto propio del que habla la autora me ha servido para establecer la metáfora condensadora y fundante de este trabajo, que he rebautizado como espacio propio.

$\mathrm{Su}$ gestación tiene en cuenta el análisis de la socialización de género a la que somos expuestas desde que nacemos, incluso antes, y se centra en aportar un instrumento práctico de trabajo, un mapa conceptual para acompañar en su viaje a aquellas mujeres que por diversos motivos han perdido la conexión con un espacio propio seguro, legitimador y nutricio.

Por supuesto este espacio propio, es algo que va más allá de lo meramente geográfico para ser sobre todo un lugar auto referencial en la psique. Está en estrecha relación con cómo hemos ido configurando y qué vivencia tenemos de nuestra identidad de género. Tiene que ver con nuestra autoestima y autoconcepto, con la capacidad de negociación de nuestras relaciones personales y amorosas, con el manejo de nuestro mundo objetivo y subjetivo y con el equilibrio o no, entre la mirada propia y la mirada ajena.

El espacio propio alberga una determinada relación con nuestros deseos y con aquellos mandatos, creencias y valores que nos impiden manifestarlos o llevarlos a la práctica.

Si bien la biografía y las peculiaridades caracteriales hacen de la identidad de cada persona un asunto muy particular, en general, podemos aludir a ciertas características generales en relación a la configuración de la identidad femenina.

Otras autoras han escrito ya largo y tendido acerca de esta subjetividad ${ }^{2}$. Por mi parte iré hilando el relato de lo que quiero transmitir destacando algunos aspectos, que condensaré en esta ocasión básicamente en dos cuestiones: vinculación y soledad.

En general la soledad goza de muy mala prensa porque la asociamos a un sentimiento de orfandad, de desolación, de sentirse desconectado del mundo.

LEVINTON DOLMAN, Nora [2000(2010)] El superyó femenino. La moral en las mujeres. BOURDIEU, Pierce [2000(2013)] La dominación masculina. MIEDZIAM, Myriam (1995) Chicos son, hombres serán. LAGARDE Y DE LOS RÍOS, Marcela (2000) Claves feministas para la autoestima de las mujeres. LÓPEZ FERNÁNDEZ CAO, Mángeles (2001) Geografías de la mirada: género, creación artística y representación. En definitiva, son innumerables en este trabajo las autoras y autores que han nutrido y trabajado esta idea de la configuración de la identidad femenina por lo que en la bibliografía se añaden algunos títulos más a modo de referencia sin quedar recogidos en este trabajo todos los referentes que han nutrido esta idea. 


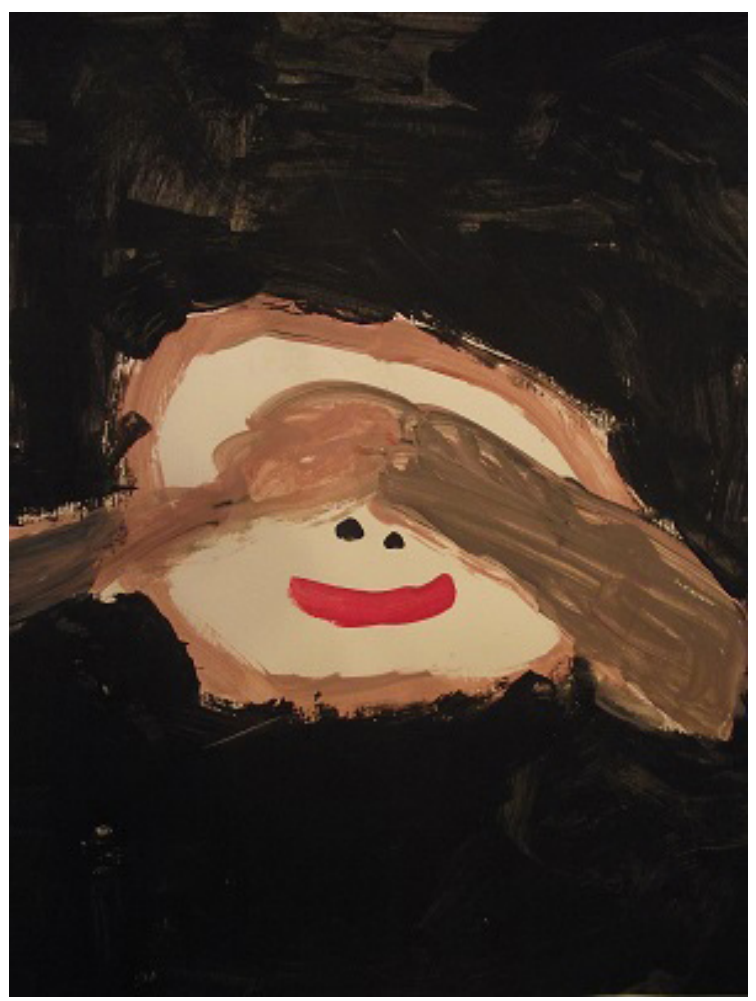

Orfandad. Obra realizada por una niña de 9 años en el contexto de un taller de arteterapia con menores a la espera de resolución de medidas judiciales en relación a su tutela y residentes en un centro de menores.

Decía Alejandra Pizarnik en uno de sus poemas:

"He desplegado mi orfandad sobre la mesa, como un mapa.

Dibujé el itinerario hacia mi lugar al viento.

Los que llegan no me encuentran

Los que espero no existen."

( PIZARNIK, Alejandra. 2007, p. 34)

Está la soledad de quienes literalmente o no tan literalmente, aunque a veces con efecto parecido, han sido abandonados a su suerte, a menudo en el momento en que más lo necesitaban. Está la soledad de la locura y del eco en la cabeza de voces irreconciliables. Está la soledad de quienes viven de espaldas a sí mismos, porque todavía hay cosas dentro que no pueden ser miradas y aceptadas. La soledad de la enfermedad, que hace que algunos estén dejando poco a poco de escuchar el ruido de la vida alrededor. Está la soledad del olvido.

Está la soledad de quienes fueron traicionados por aquellas personas que se supone que debían haberles protegido, a menudo en periodos cruciales de sus vidas. Está la soledad de la exclusión. La soledad del desarraigo. La soledad de sobrevivir a la línea genealógica que nos precede, o de sobrevivir a toda tu familia. Está la soledad 
del duelo. La soledad de quienes han perdido algo que sienten irreparable. Está la soledad del miedo a salir al mundo y, a crear lazos, a lanzarse a la aventura de vivir, porque vivir siempre es un riesgo.

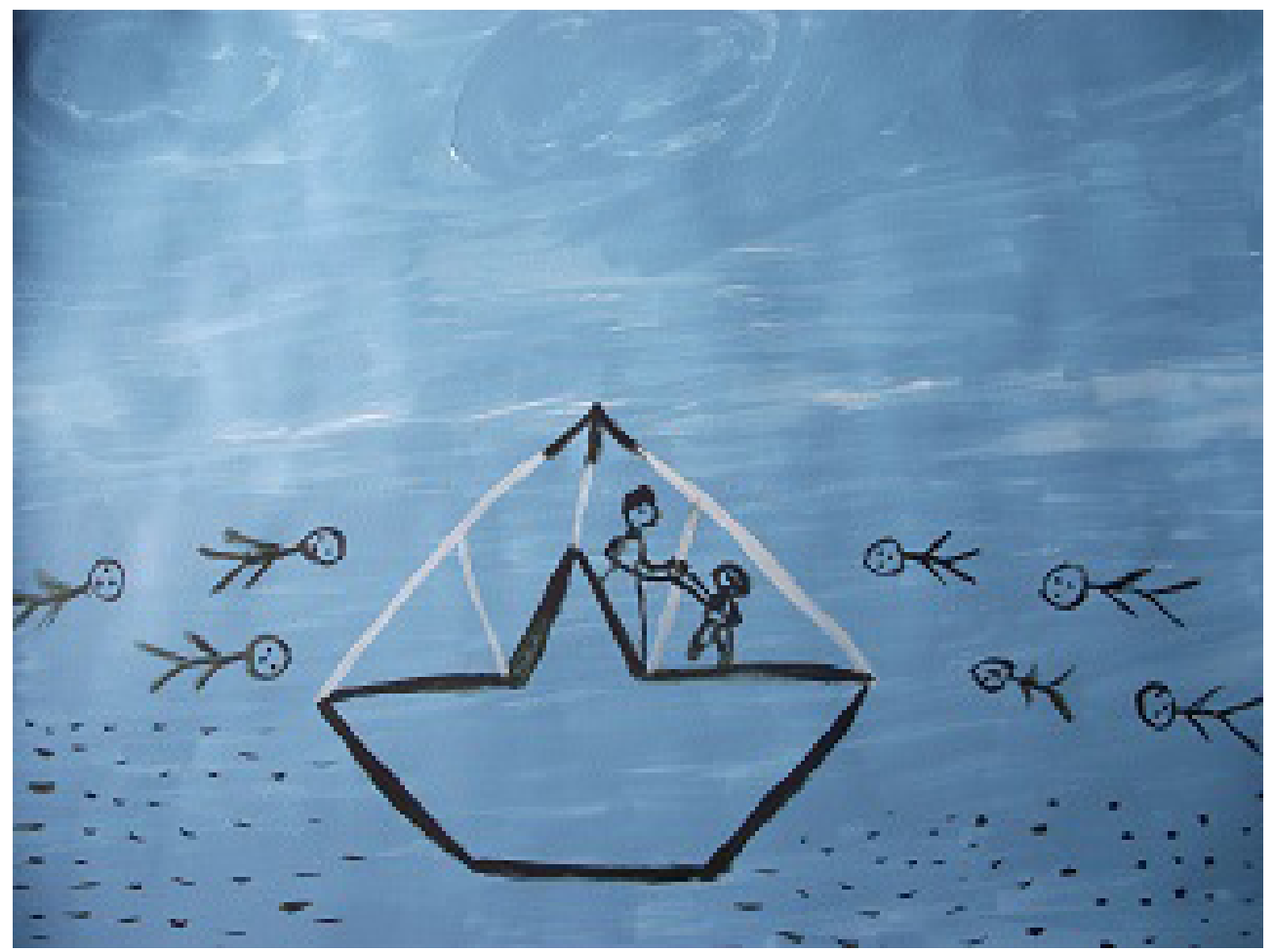

Naufragio. Obra realizada por una mujer de 48 años en el contexto de un taller de arteterapia llevado a cabo en una Casa de acogida para mujeres víctimas de violencia.

Hay una soledad desoladora en este dibujo de una mujer que después de haber sido maltratada por la vida en su infancia, cuando por fin adulta, después de un tiempo, logra volver a confiar en una pareja, un día descubre que a través de los años ha ido sucumbiendo al chantaje emocional y a un trato denigrante por parte de esta. En este dibujo ella expresó que en el centro estaba ella salvando a su pareja, "siempre quería salvarle" dijo, y todos los demás están muertos como en una especie de naufragio. Es el naufragio al que esta mujer ha sobrevivido en soledad, porque para poder alejarse de esta persona tuvo que alejarse también de toda su familia. Echa mucho de menos a su hija y a su nieta que aún siguen viviendo en su país de origen.

Sobrevivir al "naufragio" suele llevar a vivir una condición interna de apátrida, una especie de desarraigo existencial que busca consciente o inconscientemente regresar. No regresar a un lugar concreto sino a un lugar metafórico que tiene que ver con el momento en el que una se sintió integrada consigo misma y con el mundo, con sus sensaciones, emociones y pensamientos.

Como decía, en general, la soledad, goza de muy mala prensa. Pero como bien decía Nietzsche (Nietzsche, $1883 ; 183)$ una cosa es estar solo y otra cosa muy dife- 
rente es estar abandonado. Si echamos un vistazo a la lengua encontramos que por ejemplo la lengua anglosajona tiene una palabra diferente para cada uno de estos tipos de soledad. Loneliness sería la soledad del que se siente apartado y desconectado del mundo o de sí mismo, y con la palabra solitude, se refieren sin ningún tipo de juicio al simple y literal hecho de estar solo.

Porque también está la soledad como espacio de empoderamiento personal, como aquel lugar de poder, donde una se retira a procesar aquello que vive y a dialogar consigo misma. Hay que convertir la soledad, dice Lagarde, (Lagarde, Marcela. 2000, 70) en un estado placentero, de goce, de creatividad, con posibilidad de reflexión y meditación.

Sin embargo, podemos decir, volviendo al tema de la subjetividad femenina, que en general, las mujeres, hemos sido poco alentadas a experimentar la autonomía y la soledad como espacios de empoderamiento personal, cualidades ambas por cierto más que deseables para el ejercicio de la creación.

Somos construidas en lo social y en lo psicológico como seres en relación. La ética del cuidado enmarca nuestra identidad en esquemas referenciales que casi siempre incluyen a los otros como prioridad, en general a aquellas personas a las que amamos o con las que compartimos afectos.

Probablemente para poder disfrutar de esta otra soledad se necesita pasar por el dolor y la angustia de superar el miedo a estas otras soledades que nos desconectan del mundo y de nosotras. Pero sobre todo hay que pararse a reflexionar, cuanto de nosotras mismas estamos dispuestas a ceder, claudicar y traicionar para complacer al otro y que no nos abandone o para no lanzarnos a la valentía de abandonar relaciones que no nos hacen evolucionar sino involucionar. Cuantas concesiones estamos dispuestas a hacer para recibir el amor y el reconocimiento de los otros. Se darán aquí versiones más o menos graves de lo que la filósofa feminista Amelia Valcárcel (Valcárcel, Amelia. 2009; 229 y ss) bautizó hace mucho tiempo como "la ley del agrado".

Es deseable que las mujeres gravemente heridas puedan conocer y sostener esta parte vulnerable y necesitada que busca constantemente la mirada aprobatoria de los demás y que no puede concebirse, al menos de forma lo suficientemente sostenida, como un ser también autónomo y valioso por sí mismo.

Este aspecto guarda relación con algo de las personas gravemente heridas y también con algo propio de una identidad femenina en la que en general se nos ha educado para ser miradas más que para mirar, para ser deseadas más que para desear y para ser objeto de deseo más que sujetos deseantes.

Todo esto nos coloca en una situación de mucha dependencia respecto al ambiente externo y en la que generalmente las necesidades de los otros acaban por empañar las propias.

Al hablar del desarrollo emocional temprano del individuo, Winnicott describía una inicial organización ambiente - individuo, en la que poco a poco, si no existen fallas en el ambiente, se va diferenciando el ser como un ente separado e individualizado. Y describe el movimiento en el que tiene lugar esta diferenciación como un movimiento que parte del centro (Winnicott, D; 1965). 


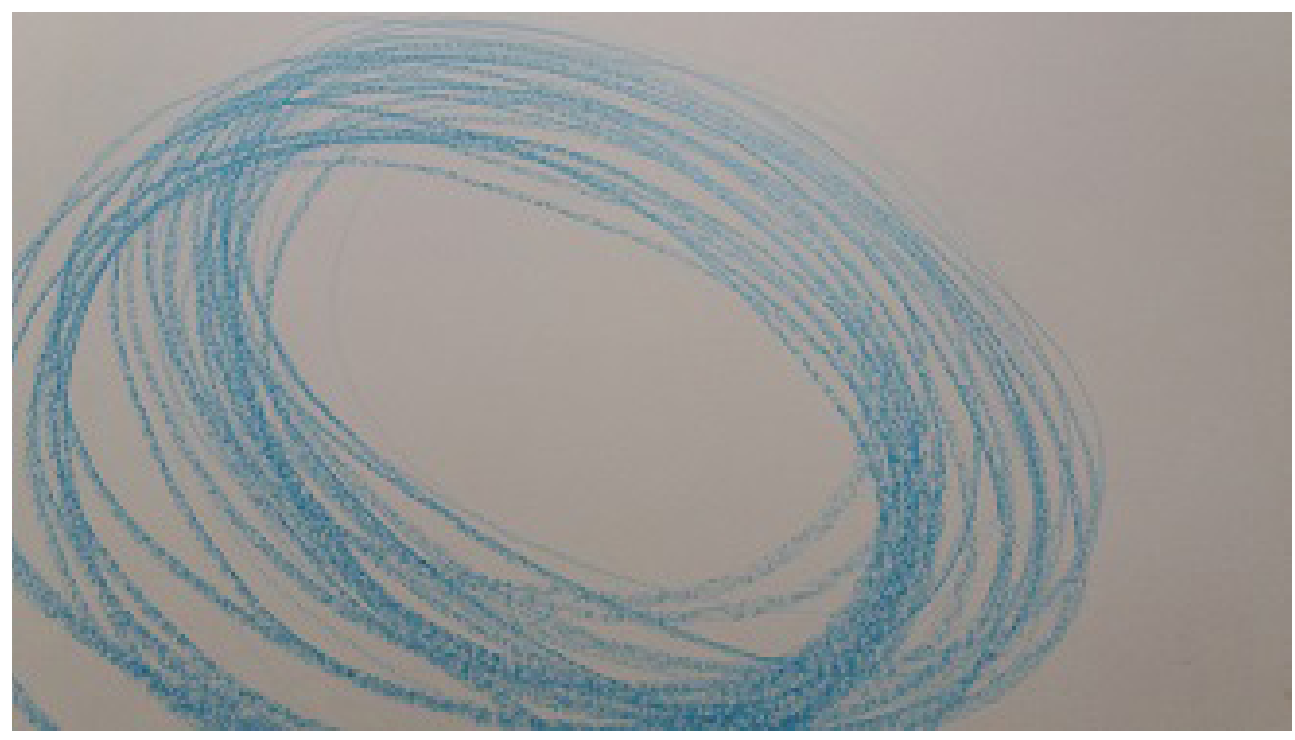

Movimiento Centrífugo. Obra procedente de un taller de arteterapia para mujeres realizada por una mujer joven

El mismo autor nos habla de que fallas importantes en este ambiente primigenio de desarrollo pueden dar lugar a traumas más o menos graves e impedir la expresión de lo que él llamará el verdadero self, ese que se mueve de dentro hacia fuera, creando y hallando el mundo desde sí, en pos de la existencia de un falso self, que se basa en lo de fuera para moverse, que se mueve centrípedamente, y se encuentra, en definitiva, al servicio de proteger al verdadero self. La función defensiva de este falso self se organiza en torno a la disociación de las propias necesidades.

Este asunto de la dependencia y las necesidades es un asunto muy grande y que impregna toda relación terapéutica, tanto a nivel transferencial como contratransferencial.

Pero quiero colocar una mirada concreta en la reflexión acerca de cómo esta dependencia del ambiente externo nos lleva a establecer vínculos en los que el espacio propio se ve amenazado o imposibilitado de alguna manera.

Esta amenaza puede tener forma de invasión, de chantaje amoroso, de manipulación, de idealización y un largo etc. Sabemos que cuanto más dañada está la persona más instrumentalización del vínculo suele tener lugar.

En este sentido, el espacio propio que propongo como marco de trabajo, vendría a ser como la casa del self verdadero de Winnicott, como la carcasa de ese nido de seguridad que necesitamos para descubrir el mundo de manera segura y enriquecedora. 


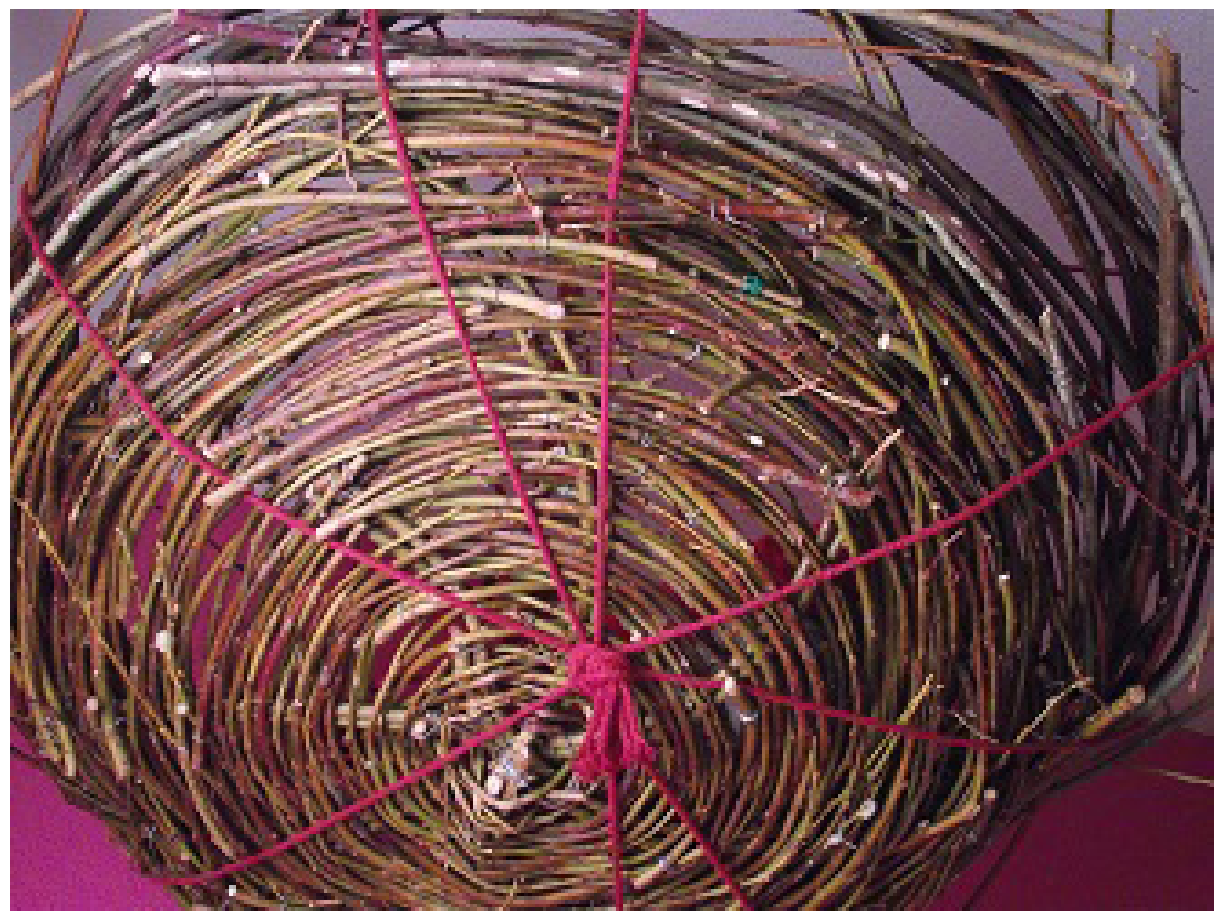

El nido. Obra propia

Porque el espacio propio es también ese nido en el que finalmente nos podemos sentar a incubar, en el que después de dar muchas vueltas y caminar, a veces pareciera que, en sentido errático, una puede pararse y escribir, pintar, bailar, fotografiar.

Una puede pararse y abrirse a lo que tenga que ser expresado, sea lo que sea, sin juzgar. Puede dar lugar y cobijo a lo está por emerger.

Una puede dar cauce a esa creatividad que fluye de la vida misma, en el sentido más biológico del término, al estar conectada con cierto sentido de la propia existencia.

Para esto es necesario poder entrar y salir, de motu proprio, de un estado de soledad placentera. En este sentido no siempre es necesario estar literalmente sola, o vivir la llamada solitude de la lengua inglesa, para poder estar conectada con el espacio propio.

El espacio propio alude también a la idea de todo aquello que nos es ajeno y cuenta con unos límites que contienen lo propio y lo separan de lo ajeno, una membrana que nos separa del mundo y que a la vez nos permite establecer contacto con el exterior. Aprender a manejar ese límite, estar con el otro sin dejar de estar con una misma, no es tarea sencilla para nadie, máxime cuando hablamos de personas gravemente heridas.

En este aprendizaje es necesario sentir que existe un eje interno de referencia, que si bien puede ser flexible en términos identitarios, mantiene perenne una especie de estructura base. 
Este espacio propio tiene también que ver con la paciencia y el cuidado que permitan a la persona construir de nuevo esa especie de urdimbre interna que le sirva de sujeción frente a los vaivenes de la herida puesta en movimiento en el mundo.

Para las personas que han sufrido graves traumas es una tarea muy complicada encontrar a quienes puedan y estén dispuestos a escuchar su verdad. Porque poner voz a esta verdad no solamente implica revivir el horror de lo vivido y convertirse de nuevo en lo pequeña que una fue en un momento dado frente a algo que su cuerpo/ psique no pudo integrar ni comprender.

Porque poner voz a esta verdad implica también adentrarse en un terreno identitario novedoso, el de aquel o aquella que se siente con el poder de narrar, de decir, de acusar. Un terreno quizás muchas veces imaginado pero pocas veces habitado en ese espacio real que compartimos objetivamente con los otros.

Desde el acompañamiento arte terapéutico a veces habrá que colocar almohadas alrededor de un bebé que duerme plácidamente en el centro de la cama. Porque el espacio propio también es un lugar donde poder dejarse caer, donde poder derrumbarse y soltar el peso de la culpa. Otras veces quizá haya que poner un poco de luz para que la persona pueda alumbrar en compañía algunos de sus monstruos.

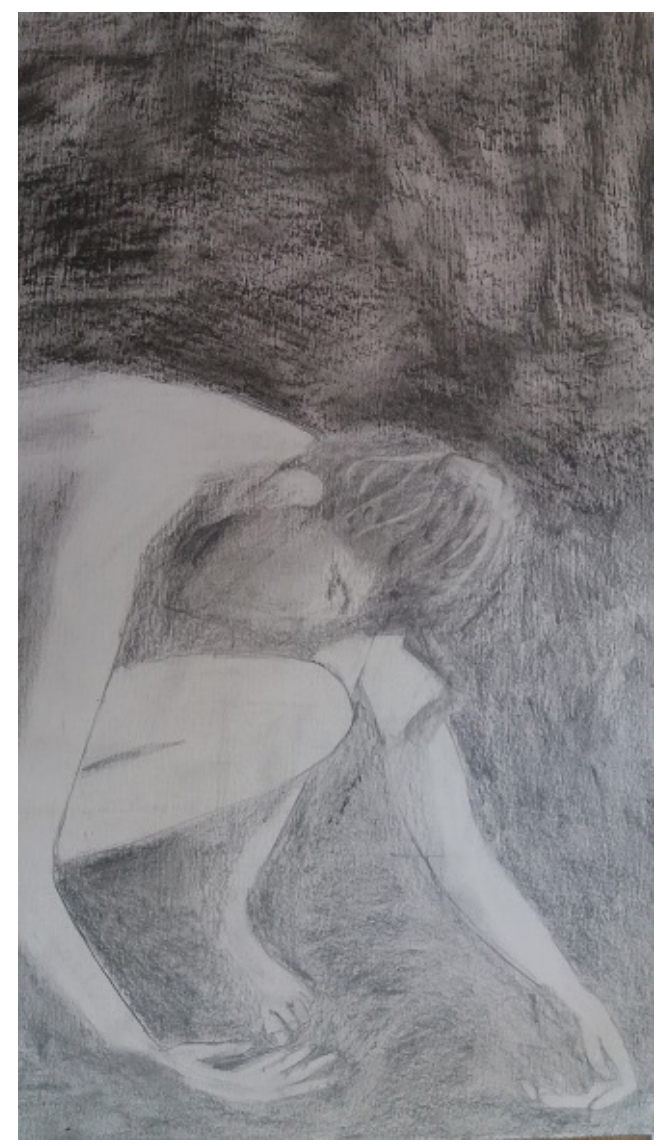

Cuerpo rendido. Obra propia 
Y sobre todo habrá que caminar hacia él apoyadas en el conocimiento intuitivo de nuestro cuerpo, porque este procesó las emociones dolorosas en un lenguaje que solo él descifra si podemos pararnos a escucharlo con atención.

El espacio propio es un lugar que se sitúa en un presente que más o menos, ha hecho las paces con su pasado y que mira al futuro sabiendo que se construye día a día y con la confianza en que la vida nos irá trayendo aquello que necesitamos en cada momento. Sin duda podremos ir diferenciando la entrega amorosa en la que una puede crecer del sometimiento que limita nuestro libre desarrollo.

Cada espacio propio es particular y cambiante y con su transformación jugamos a lo largo de este trabajo.

El espacio propio es un mapa de referencias de este viaje que toda mujer lleva a cabo en algún momento de su vida en la búsqueda de la reconexión consigo misma. Es un mapa que está escrito en la piel, donde cada lunar y cada marca tienen un sentido y forman parte de una particular geografía. Manejar esta geografía tiene que ver también con el conocimiento o el re-conocimiento de la pertenencia y del origen.

Así tendremos un mapa para volver a casa. Cuando una maneja sus coordenadas, puede ir y volver, puede enredarse, desordenarse, confundirse, y lanzarse al caos porque sabe volver al centro, a la seguridad del nido y de la casa interna.

Cuando la persona ha pasado por situaciones traumáticas, este irse de la propia casa, puede suponer, como muestra este dibujo, un laberinto difícil de transitar y la persona es impedida de hacer su viaje mítico por monstruos peligrosos y aterrorizantes. $Y$ entonces el espacio propio se convierte en una maraña absurda de criterios.

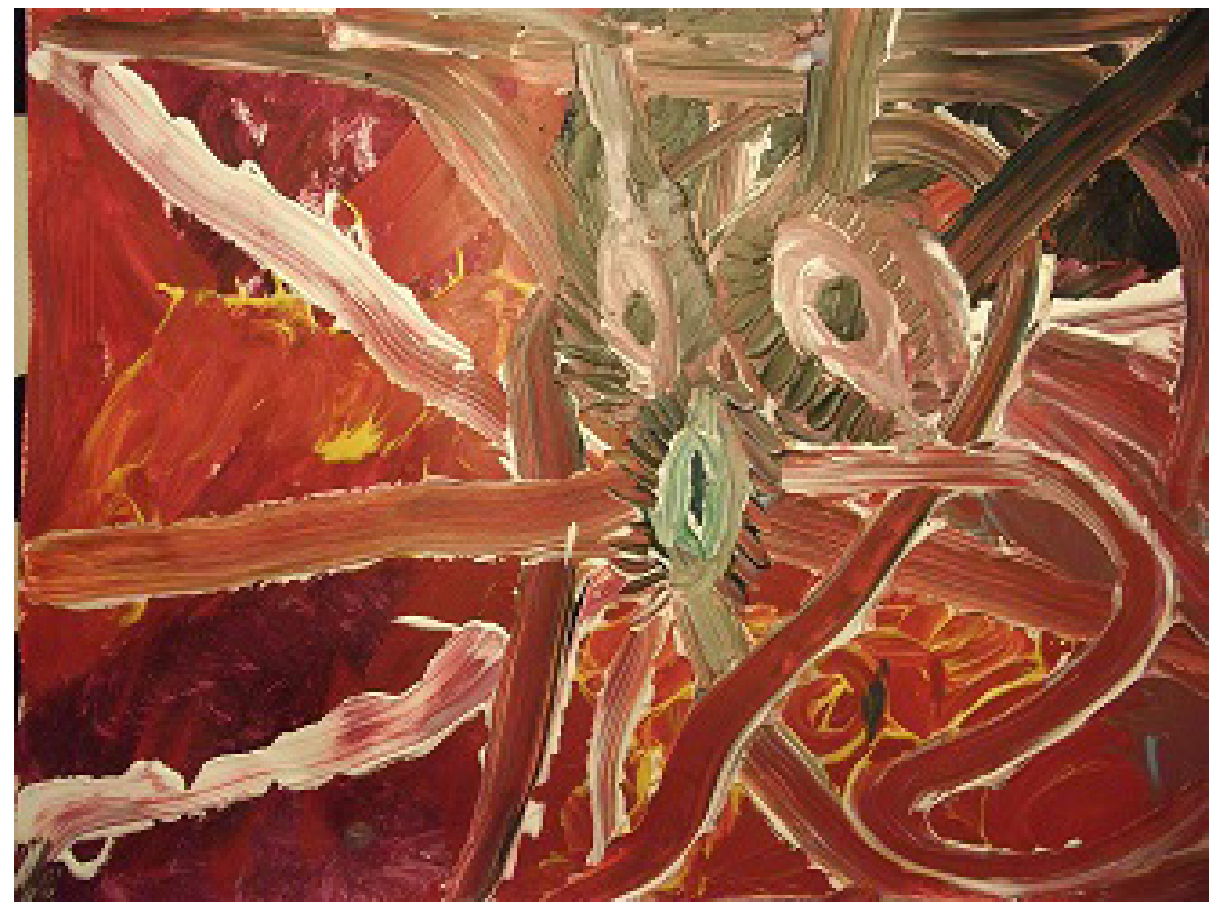

El laberinto y el monstruo. Obra realizada por una mujer de origen extranjero y de mediana edad en el contexto de un taller de arteterapia realizado en una Casa de acogida para mujeres víctimas de violencia) 
O en una serie de personajes internos antagónicos y desacordes pero que a través del arteterapia pueden ponerse al menos a dialogar.

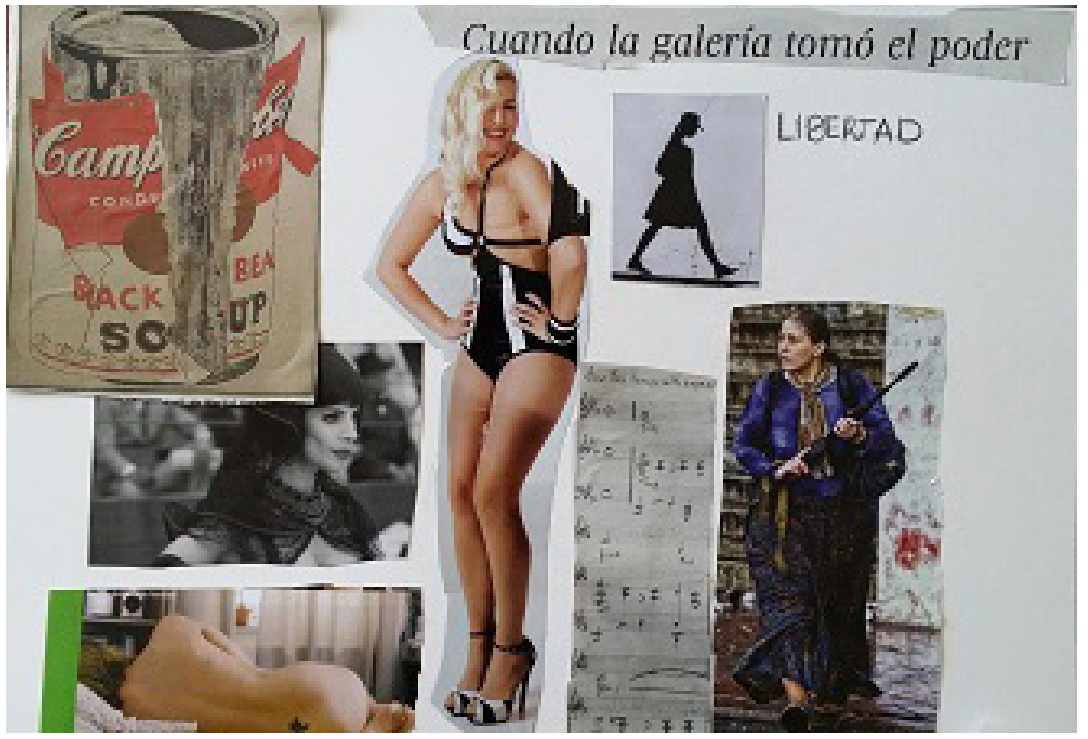

Diferentes personajes. Obra producida por una paciente mujer en la consulta privada)

A veces la injerencia y la invasión externa se sienten de tal forma, que la persona necesita hacer uso de sus cajas, para proteger su espacio propio. Al principio de su terapia, solo desde el espacio cerrado de las cajas, podía esta paciente relacionarse, pedir, suplicar, desbordarse, sin el miedo que le daría estar totalmente expuesta.

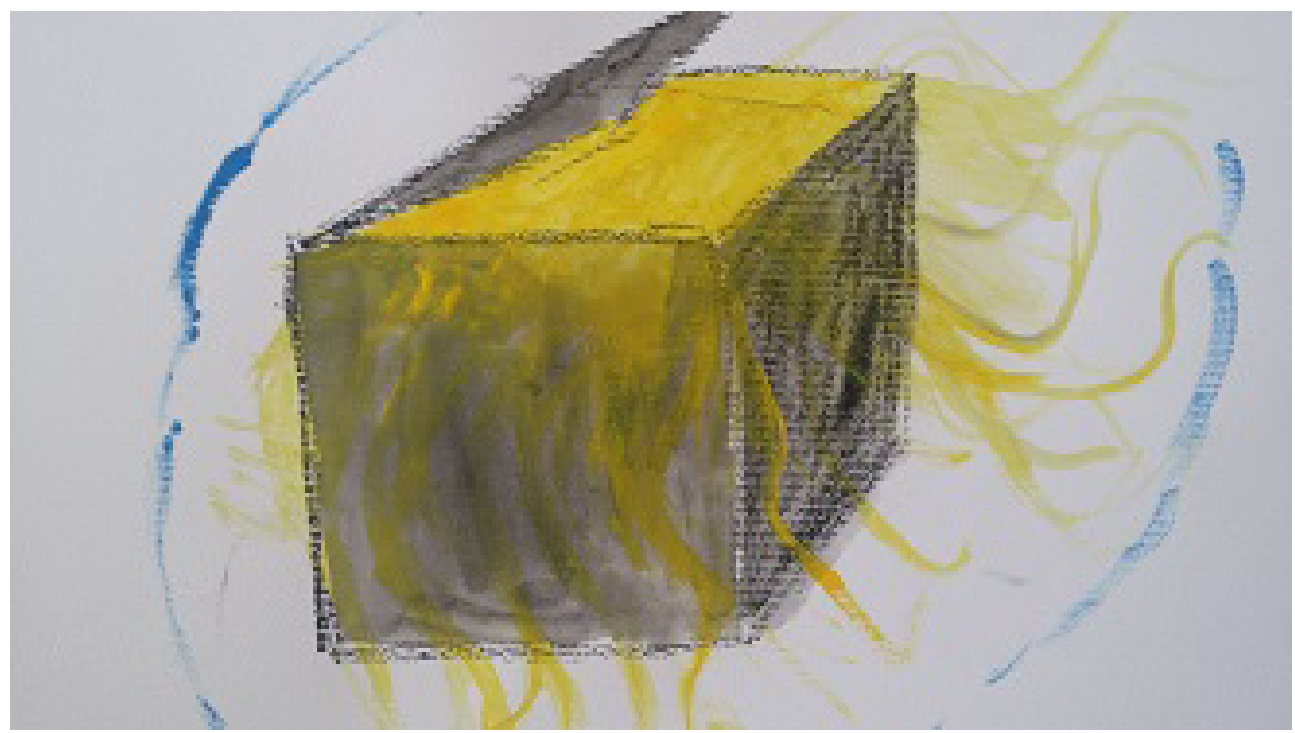

Las cajas. Obra producida por una paciente mujer en la consulta privada 
En otras ocasiones resulta que ese espacio propio de creatividad y conexión interior no se encuentra accesible pero la persona cuenta con la idea, con la imagen, tiene un mapa escondido en algún lugar sobre cómo hallarlo, tiene un hilo con el que sabe que puede coser con sus botones un espacio propio con más luz.

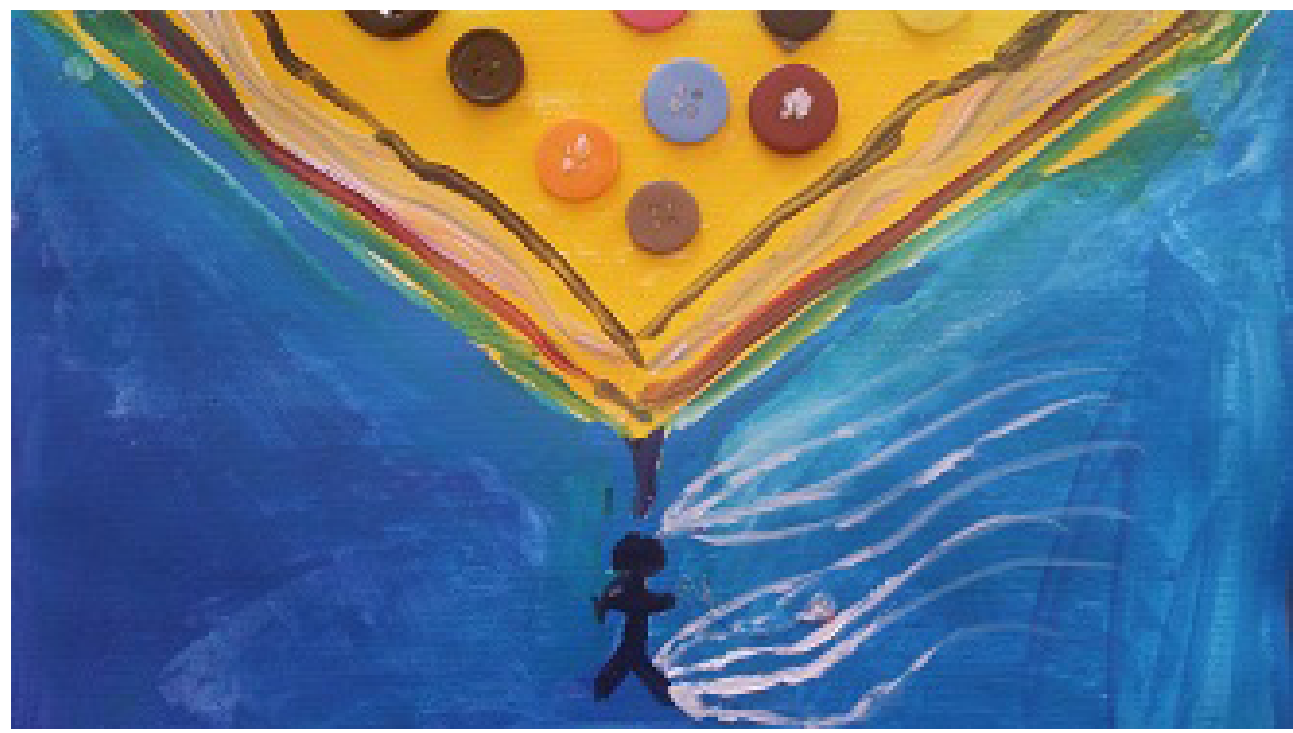

Cometa de botones. Obra producida por una paciente mujer en la consulta privada)

El taller de arteterapia para mujeres ofrece un lugar para despejar el bosque de miradas ajenas y de juicios más o menos asentados en nuestro superyó.

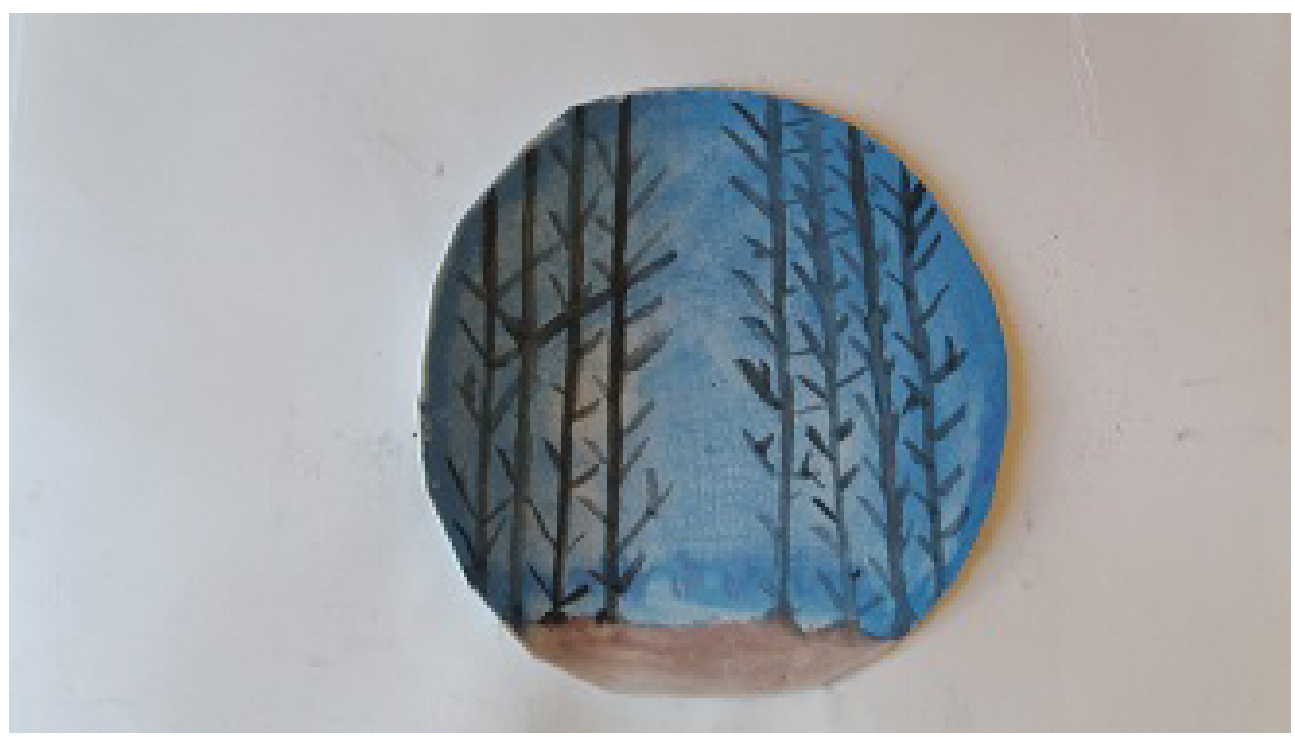

El claro del bosque. Obra producida por una paciente mujer en la consulta privada 
El espacio propio resuena de este modo en las palabras de la filósofa María Zambrano cuando dice que:

"el claro del bosque es un centro en el que no siempre es posible entrar. (...). No hay que buscarlos ni buscar nada en ellos. (...). Y se recorren los claros del bosque como se han recorrido las anclas. Como los claros, las anclas son lugares vacíos dispuestos a llenarse, lugares de la voz donde se va a aprender de oído" (ZAMBRANO, María (2011, p.121))

Una puede habitar su espacio propio cuando sabe internamente que no está en la obligación de demostrarle nada al mundo, y no tiene que excusarse, simplemente es, lo que es, con sus miserias y sus grandezas. Y esta es una actitud de aceptación a la que se puede llegar solamente libre de culpa. Ahí una está satisfecha con lo que es y con lo que tiene y descubre que quizá no necesita todo aquello que ambicionaba.

Como expresa maravillosa y bellamente Cristina Martín en este poema:

“...me observo

Ambicionando lo que no necesito

Por mera imitación

De lo que otros necesitan

Entonces me grito dentro

Me grito dentro de mi cabeza pelirroja

¡Todo es más fácil!

No necesitas el elogio,

Ni que te miren,

Ni verte rodeada de certeza

No necesitas ser de las primeras

Ni conocerte del todo

Ni ser la más amada

Ni dos hileras de zapatos

No necesitas ser lo que se tiene que ser

No quieres ser lo que se tiene que ser (...)

MARTÍN, Cristina (2011, p. 33)

En este sentido creo entender que todo este mapa referencial es propicio tanto para el trabajo con grupos de mujeres en general como con personas que han sufrido traumas. En cada tipo de trabajo y en función de las y/o los participantes existirán deferentes niveles de intervención y profundidad.

Habrá que poner especial atención al modo en que este espacio propio ha dejado de ser el lugar desde donde la persona ocupa su propio centro de gravedad y pone en juego su propio criterio para entender el mundo y relacionarse con él. Habrá que ayudar a vaciarlo de algo de toda esa culpa y resentimiento que las personas que sobreviven a los naufragios suelen acumular. Probablemente estaremos frente a cuerpos que se han vuelto temerosos y rígidos hasta límites insospechados.

El abandono siempre encierra una búsqueda insaciable del amor incondicional que se perdió. Y con esto también habrá que trabajar, probablemente, sabiendo que como acompañantes somos depositarias en muchas ocasiones, de las formas que puede tomar esta búsqueda. 
Habrá que ser consciente en el acompañamiento que realizamos de la importancia de nuestra mirada en relación a otra que busca ser "sostenida" y que gradualmente hay que alentar a sostenerse por sí misma. Somos hijos de los vínculos y con ellos nos vamos narrando. Como decía Ángel González con un verso, "yo sé que existo porque tú me imaginas" (GONZÁLEZ, Ángel, 1998, p. 19).

Es el bebé que busca tu mano para apoyarse y dar otro pasito más y también el bebé que en ese espacio de seguridad va venciendo sus miedos y creciendo en autonomía. Pero para ello necesita antes pasar por esta etapa, en la que sabe que existe porque tú lo imaginas, necesita tener esa experiencia para existir más adelante y plenamente por sí mismo.

\section{Bibliografía}

Alario Trigueros, $\mathrm{M}^{\mathrm{a}}$ Teresa (2008): Arte y Feminismo. San Sebastián. Editorial Nerea.

Abello Blanco, Augusto y Liberman, Ariel, (2011) Una introducción a la obra D. Winnicott. Contribuciones al pensamiento relacional. Madrid. Editorial Ágora Relacional.

Altable Vicario, Charo (2005) Penélope o las trampas del amor. Valencia. Edicions Culturals Valencianes.

Cyrulnik, Boris (2002): Los patitos feos. La resiliencia: una infancia infeliz no determina la vida. Barcelona. Editorial Gedisa.

Fiorini, Héctor Juan (2006): El psiquismo creador. Teoría y clínica de procesos terciarios. Buenos Aires. Ediciones Nueva Visión.

González, Ángel (1998) Palabra sobre palabra. Barcelona. Editorial Seix Barral.

Herman, Judith (1992) Trauma y recuperación. Cómo superar las consecuencias de la violencia. Madrid. Editorial Espasa Calpe.

Lagarde y de los Ríos, Marcela (2000), Claves feministas para el poderío y la autoestima de las mujeres. Madrid. Editorial Horas y Horas.

López, Fernández Cao, Ma Ángeles (2001): Geografías de la mirada: género, creación artística y representación. Madrid. Instituto de Investigaciones Feministas.

Munárriz, Jesús (2006) Los jueves poéticos en La Casa del Libro. Recitales de jóvenes poetas. Madrid. Editorial Hiperión.

Martín, Cristina (2011) La mujer precipicio. Barcelona. Editorial Libros del Silencio.

Nietzsche, Friedrich [1883 (2003)] Así habló Zaratustra. Madrid. Editorial EDIMAT Libros S.A.

Ogden, Pat, Minton, Kekuni y PAIN, Clare, (2011) El trauma y el cuerpo. Un modelo sensoriomotriz de psicoterapia. Bilbao. Ediciones Desclée de Brouwer.

Pelegrina Cetran, Héctor (2006): Fundamentos antropológicos de la psicopatología. Madrid. Ediciones Polifemo.

Pizarnik, Alejandra (2007) La extracción de la piedra de la locura. Otros poemas. Madrid. Ediciones Visor.

Valcárcel, Amelia (2009) Feminismo en el mundo global. Madrid. Ed. Cátedra.

Woolf, Virginia [1929 (2014)] Una habitación propia. Madrid. Editorial Alianza.

Winnicott, Donald [(1965b) 1992] Los procesos de maduración y el ambiente facilitador. Barcelona. Editorial Paidós.

Winnicott, Donald [1971 (1992) Realidad y juego. Barcelona. Editorial Gedisa. 
Winnicott, Donald [1987(1990)] El gesto espontáneo. Cartas escogidas. Barcelona. Ediciones Paidós.

Zambrano, María (2011) Claros del bosque. Madrid. Ediciones Cátedra. 